\title{
Aquífero Guarani: diagnóstico tridimensional do direito às águas subterrâneas
}

\section{Guarani Aquifer: Three-dimensional Diagnosis of the Right to Groundwater}

Edieter L. Cecconello - Doutor em Direito Público, pela Universidad del Museo Social Argentino (UMSA). Professor de Direito Minerário e Recursos Hídricos da Faculdade de Direito na Universidade Federal do Sul e Sudeste do Pará (UNIFESSPA). E-mail: el.cecconello@gmail.com

\section{Resumo}

Esse estudo reorganizou o debate sobre o Aquífero Guarani, usando a metodologia tridimensional do jurista Miguel Reale, compreendendo as categorias fato, norma e valor. Reforçando esse método, foram acrescentadas contribuições pontuais da teoria da tragédia dos comuns, da teoria da sociedade de risco e da teoria da sociedade anárquica de Estados, que auxiliaram na descrição dos aspectos valorativos, fatuais e sociais do tema. Como resultado, esse estudo reforçou a importância do olhar interdisciplinar sobre o Aquífero Guarani, enfatizando o princípio da sustentabilidade ambiental.

\begin{abstract}
This study reorganized the debate on the Guarani Aquifer, using the threedimensional methodology of the jurist Miguel Reale with the categories of fact, norm and value. Reinforcing this method, there were added specific contributions of the theory of tragedy of the commons, of the theory of the society of risk and of the theory of the anarchic society of states that helped in the description of the evaluative, factual and social aspects of the subject. As a result, this study methodologically reinforced the importance of the interdisciplinary view on the Guarani Aquifer, emphasizing the principle of environmental sustainability.
\end{abstract}

\section{Palavras-chave}

Aquífero Guarani. Tridimensionalidade. Sustentabilidade. Direito internacional.

\section{Keywords}

Aquifer Guarani. Three-dimensionality. Sustainability. International right. 


\section{INTRODUÇÃO}

O objetivo geral desse estudo é produzir um diagnóstico jurídico sobre o aquífero Guarani, localizado na América do Sul, aplicando o método tridimensional do jurista brasileiro Miguel Reale (1960, 2002) pelo qual se projetam, dialeticamente, as categorias fato, norma e valor. O objetivo específico desse estudo é sistematizar a legislação mínima ao direito às águas subterrâneas do aquífero Guarani ao lado dos valores culturais e fatos contemporâneos inter-relacionados, procurando descobrir o fio condutor ou princípio jurídico preponderante que anima o debate desse tema no conjunto dialético da tridimensionalidade.

O Sistema Aquífero Guarani faz parte da Bacia Geológica Sedimentar do Paraná e é um importante corpo hídrico subterrâneo e transfronteiriço entre Brasil, Argentina, Paraguai e Uruguai, sendo considerado entre uma das maiores reservas de água doce subterrânea do planeta. No Brasil são 735.917,75 km², distribuídos entre oito estados das regiões Centro-Oeste, Sudeste e Sul do país. Os dados fornecidos pelo Ministério do Meio Ambiente, do Governo Federal Brasileiro (OEA, 2009, p.16), informam que o Sistema Aquífero Guarani possui um volume acumulado de $37.000 \mathrm{~km}^{3}$ e área estimada de $1.087 .000 \mathrm{~km}^{2}$ como um todo.

Notícia veiculada pelo site Ecoa, organização não governamental do estado de Mato Grosso do Sul, Brasil, afirma, por sua vez, que:

O Aquífero Guarani constitui-se em uma importante reserva estratégica para o abastecimento da população, para o desenvolvimento das atividades econômicas e do lazer. Sua recarga natural anual (principalmente pelas chuvas) é de $160 \mathrm{Km}^{3} /$ ano, sendo que desta, $40 \mathrm{Km}^{3}$ /ano constitui o potencial explotável sem riscos para o sistema aquífero. As águas em geral são de boa qualidade para o abastecimento público e outros usos, sendo que em sua porção confinada, os poços têm cerca de $1.500 \mathrm{~m}$ de profundidade e podem produzir vazões superiores a $700 \mathrm{~m}^{3} / \mathrm{h}($ ECOA, 2018, p. 01).

\section{MÉTODO DE REORGANIZAÇÃO DAS IDEIAS}

Segundo o jurista Miguel Reale (2002, p. 556), "todo ser humano possui um centro axiológico de gravidade que garante o equilíbrio de nosso ser pessoal". Consequentemente, toda a tomada de posição é inseparável de qualquer experiência axiológica, manifestando-se tanto no plano individual e coletivo 
como ato decisório, resultante de um ato de preferência entre valores (REALE, 2002, p. 557). Portanto, se o valor e o fato se mantêm distintos, exigindo-se reciprocamente em condicionalidade recíproca, "podemos dizer que há entre eles um nexo ou laço de polaridade e de implicação" (MONTARROYOS, 2012, p. 01). Porém, cada esforço humano de realização de valores é sempre uma tentativa, nunca uma conclusão, dentro de um processo que Reale menciona como processo dialético de complementaridade (REALE, 2002, p. 571).

Assim, a atualização dos valores depende sempre das circunstâncias e dos critérios contingentes de conveniência e de oportunidade, dos quais decorre a preferência por esta ou aquela norma dentre as múltiplas vias compatíveis com as mesmas exigências axiológicas. $\mathrm{Na}$ realidade, fato e valor, fato e fim, estão um em relação com o outro em dependência ou implicação recíproca. Nesse contexto, Reale (2002) menciona a regra vigente deve ser "sempre uma baliza ao comportamento do juiz, que, no entanto, não pode deixar de valorar o conteúdo das regras. Ele, juiz, enquanto homem, já participa dela e pertence às circunstâncias de sua 'temporalidade"' (REALE, 2002, p. 583).

Em suma, a palavra Direito pode ser apreendida por abstração, em tríplice sentido, segundo três perspectivas dominantes, a saber: 1) o Direito como valor do justo, estudado pela Filosofia do Direito na parte denominada de Deontologia Jurídica, ou no plano empírico e pragmático da Política do Direito; 2) o Direito como norma ordenadora da conduta, objeto da Ciência Jurídica ou Jurisprudência e da Filosofia do Direito no plano epistemológico; e 3) o Direito como fato social e histórico, objeto da História, da Sociologia e da Etnologia (MONTARROYOS, 2012; REALE, 2002, p. 509).

\section{CULTURA DO DESPERDÍCIO DE ÁGUA}

Segundo o especialista Guerra (2009, p. 16), “a água é um bem vital para a existência da vida de todas as espécies e, em especial, para o ser humano", pois "sua utilização vai além do consumo orgânico, haja vista que é utilizada em diversas atividades incluindo: uso doméstico, indústria, agricultura etc." (GUERRA, 2009, p. 16). Nessa direção o mesmo autor observou que "ao se desperdiçar a água, as pessoas negam seu valor e demonstram claramente uma visão míope diante dos acontecimentos presentes e futuros da humanidade [...]" (GUERRA, 2009, p. 16). 
Reforçando a preocupação com a sustentabilidade, Resende (2013a, p. 136) afirmou que "no consumo alienado o consumidor não se preocupa com a qualidade e a procedência dos produtos, mas apenas com a quantidade consumida"; diferentemente, "no consumo crítico a pessoa procura qualidade, evita excessos, e considera o direito de escolha fundamental" (RESENDE, 2013a, p. 136). Na classificatória do mesmo autor considerou-se que "no consumo consciente o consumidor, antes de comprar, indaga de onde vem o produto, quem o produziu e em que condições" e, ainda, "se foram respeitados o meio ambiente e os direitos dos trabalhadores; e a partir das respostas [obtidas] norteia a sua decisão de consumo" (RESENDE, 2013a, p. 136).

Segundo Resende (2013b, p. 301), atualmente,

os indivíduos passam a consumir com os olhos e as emoções voltados apenas para eles mesmos, em um ato extremamente individualista e egoísta, sem se preocupar com as consequências socioambientais de suas decisões de consumo. Vive-se uma cultura de consumismo.

Ainda de acordo com o mesmo autor, “[...] nossas atividades econômicas, estilos de vida e hábitos de consumo estão destruindo a biodiversidade e o planeta a um ponto quase irreversível, razão pela qual se deve reduzir ao máximo o impacto das atividades humanas na natureza" (RESENDE, 2013b, p. 301). Nesse aspecto, Resende (2013a, p. 126) recuperou a contribuição de Marx que "desenvolveu uma crítica da exploração capitalista do solo, ao ressaltar que a agricultura capitalista de larga escala perturbava a relação metabólica entre o Homem e a terra".

De acordo com o que informou a "Revista Página 22", publicada pelo Centro de Estudos em Sustentabilidade (ÁGUA..., 2014), 40\% da água para consumo é desperdiçada no Brasil. Preocupados com essa realidade, Bacci e Pataca (2008, s. p.) afirmaram que "o tema água deve estar presente no contexto educacional [...] com enfoque na ética e na formação do cidadão consciente do lugar que ele ocupa no mundo". Na opinião dos mesmos autores citados "a educação para a água não pode estar centrada apenas nos usos que fazemos dela, mas na visão de que a água é um bem que pertence a um sistema maior, integrado, que é um ciclo dinâmico sujeito às interferências humanas". Nesse sentido, o consumo ideal de água dentro do princípio da sustentabilidade deve contemplar os seguintes princípios, segundo a Declaração de Dublin, anunciada pela Conferência Internacional sobre Água e Desenvolvimento, em 1992: 
1-A água é um recurso finito e vulnerável, essencial para a manutenção da vida, do desenvolvimento e do meio ambiente; partindo-se do princípio que a água sustenta a vida, a gestão dos recursos hídricos requer uma abordagem holística, integrando o desenvolvimento económico e social com a proteção dos ecossistemas naturais. A sua gestão efetiva integra o uso do solo com os usos da água no âmbito da bacia de drenagem ou do aquífero subterrâneo;

2-A gestão e o desenvolvimento dos recursos hídricos devem ser baseados no enfoque participativo, envolvendo usuários, projetistas e governos de todos os níveis; a abordagem participativa implica o fomento à consciencialização da importância da água em todos os sectores público e privado e sugere que as decisões sejam tomadas na base, com ampla participação e consulta pública e o envolvimento dos usuários no planeamento e implementação dos Projetos;

3-As mulheres têm um papel fundamental na administração, gestão e proteção dos recursos hídricos; implícito no papel das mulheres está o processo, o que raramente se verifica nos arranjos institucionais da gestão dos recursos hídricos;

4-A água tem valor económico para todos os seus usos e deve ser reconhecida como um bem económico; este último princípio embute o conceito fundamental do reconhecimento do direito de todos à água potável e ao saneamento, a preços compatíveis (DECLARAÇÃO ..., 1992, p. 01-02)

Especialistas diversos afirmam que a expressão "sustentabilidade" é sinônimo de coerência entre o uso e a preservação consciente de um determinado bem da natureza. Ou seja, ao mesmo tempo em que a Natureza é explorada, ela é mantida para as futuras gerações. Segundo Efing e Resende, o direito ao desenvolvimento:

deve estar intimamente jungida à concretização da dignidade da pessoa e à defesa do meio ambiente, de forma que o desenvolvimento deve ser perseguido sem provocar danos ao meio ambiente ou pelo menos com o mínimo de impactos negativos na natureza, promovendo, assim, o desenvolvimento sustentável (EFING; RESENDE, 2016, p. 719).

Consequentemente, consideraram os mesmos autores que não se pode falar em desenvolvimento que não seja sustentável.

\subsection{EXTERNALIDADES NEGATIVAS}

Os efeitos deletérios da cultura do desperdício da água reforçam a utilidade da teoria conhecida como "tragédia dos comuns" (HARDIN, 1968). Existiria inicialmente abundância de água para os indivíduos que buscam 
satisfazer suas necessidades e bem-estar privado. Entretanto, havendo o risco de alguém monopolizar as reservas naturais de modo egoísta, nasce um ambiente competitivo que gera o estado de natureza hobbesiano com a "guerra de todos contra todos". Nesse contexto, segundo o filósofo Hobbes (2003), falta um poder aglutinador que impeça o ser humano de agir de modo arbitrário.

Portanto, devido à ambição desenfreada dos indivíduos e à ausência de poder público que deveria produzir informações estratégicas em benefício da ordem ecológica configura-se o estado de natureza, que é uma situação eficiente na produção de bens privados, refletindo o máximo de liberdade dos agentes racionais.

Surgem, consequentemente, externalidades negativas como poluição, violência, desordem, epidemias, escassez de recursos naturais e injustiça, que afetam a todos indistintamente, pobres e ricos, caracterizando o mal comum ou tragédia social que prejudica não só a qualidade de vida da comunidade, mas sobretudo a existência biológica de cada um.

Conforme ressaltou o neocontratualista Hardin (1968), na tragédia dos comuns "o homem racional descobre que o custo de descartar seus resíduos sem qualquer tratamento no meio ambiente é menor do que o custo de tratar esses resíduos antes de descartá-los” (SAMPAIO; LAMARE; KLOSS, 2016, p. 187). Nessa perspectiva, ainda conforme estes autores "todos os indivíduos racionais chegarão à idêntica conclusão e descartarão resíduos contaminados no meio ambiente, que, com o tempo, ficará totalmente poluído" (SAMPAIO; LAMARE; KLOSS, 2016, p. 187).

Agravando-se a crise ecológica, nesse modelo teórico pode surgir um ponto de saturação ou de mutação, com a emergência positiva de um contrato social que firmará regras, autoridades e instituições destinadas a produzir os limites da convivência humana tendo em vista fundamentalmente o bem comum.

$\mathrm{Na}$ teoria contratualista clássica de Hobbes, a solução contra a desordem ecológica é um Estado forte, o Leviatã. Semelhantemente, para os neocontratualistas contemporâneos que defendem princípios democráticos e humanistas, pode-se achar uma solução moderna para a tragédia dos bens comuns com a definição de instrumentos regulatórios de comando e de controle coletivo (SAMPAIO; LAMARE; KLOSS, 2016). Segundo os mesmos autores citados: 
O estabelecimento de critérios e parâmetros para o descarte de resíduos e a previsão de penalidades, em caso de descumprimento, poderiam tornar o descarte, sem o devido tratamento, mais custoso, criando incentivos para que o homem racional sempre descarte o resíduo tratado. Desse modo, [...] a ideia que fundamenta a tragédia dos comuns auxilia na elaboração de políticas públicas na seara ambiental e, por conseguinte, contribui para uma gestão mais eficiente desse bem (SAMPAIO; LAMARE; KLOSS, 2016, p. 187-88).

\section{FATOS CONTEMPORÂNEOS: INSUSTENTABILIDADE}

Notícia publicada pelo "Jornal do Barão", Publicação Bimestral do Curso de Jornalismo do Centro Universitário Barão de Mauá, de 2005, Brasil, destacou que o subsolo do município de Ribeirão Preto é abastecido pela água do Aquífero Guarani, a maior reserva subterrânea de água doce da América do Sul. Registrou a mesma notícia que existe uma população superior a 500 mil habitantes em Ribeirão Preto, sendo uma das poucas cidades do Estado de São Paulo abastecida integralmente pelo Aquífero Guarani (USO..., 2005).

Segundo dados do Departamento de Água e Esgoto de Ribeirão Preto (DAERP), apresentados pelo mesmo Jornal, esse município tem 99 poços artesianos em funcionamento, que são responsáveis por $13.400 \mathrm{~m}^{3}$ de água por hora. Apesar disso, alertou a notícia do jornal que “já começa a faltar água nas residências de alguns bairros. Somente na terceira semana do mês de abril de 2005, os moradores de cinco bairros da cidade tiveram problemas com a água de suas torneiras" (USO, 2005, p. 01). Além disso, informações do DAEE (Departamento de Água e Energia Elétrica), reproduzidas pelo mesmo Jornal, mostram que um dos problemas mais constantes é o desperdício da água. "Enquanto a média de consumo diária do homem é de 200 litros, em Ribeirão Preto esse número [era] de 348 litros por pessoa [em 2005]" (USO, 2005, p. 01)

Reportagem do site Ecodebate (ESTUDO..., 2011) informou que o Aquífero Guarani, que abastece o município de Ribeirão Preto, cidade do nordeste paulista, Brasil, localizada a 313 quilômetros da capital de São Paulo, estava ameaçado por herbicidas. Essa conclusão veio de um estudo realizado a partir de um monitoramento do Departamento de Água e Esgotos de Ribeirão Preto (DAERP) em parceria com um grupo de pesquisadores, que encontrou duas amostras de água de um poço artesiano na zona leste da cidade com traços de diurom e haxazinona, componentes de defensivo utilizado na cultura da canade-açúcar. Segundo a mesma reportagem: 
outro problema que pode colocar em risco o abastecimento de água de Ribeirão Preto em médio prazo é a extração exagerada de água do manancial subterrâneo. Se o mesmo ritmo de extração for mantido, o uso da água do Aquífero Guarani pode se tornar inviável nos próximos 50 anos em Ribeirão Preto (ESTUDO..., 2011, p. 01).

Os dados técnicos apresentados pela reportagem indicaram que "a velocidade do fluxo de água absorvida pela reserva é mais lenta do que se supunha. Pelas contas dos especialistas, a cidade extrai $4 \%$ mais do que poderia do manancial" (ESTUDO..., 2011, p. 01).

De acordo com o analista Souza (2009), entre as principais fontes de riscos de contaminação das águas subterrâneas estão os postos de combustíveis e de derivados de petróleo; os cemitérios; a mineração; e os lixões a céu aberto, contendo celulose, metais pesados e restos de materiais hospitalares.

O especialista Carvalho (2008) lembrou, por sua vez, que as águas subterrâneas são progressivamente contaminadas pelos curtumes; frigoríficos; usinas de açúcar; agrotóxicos; e pelos poços construídos sem tecnologia adequada. Além disso, tem grande impacto a descarga de dejetos sem tratamento de esgoto domiciliar em rios e represas que abastecem cidades e irrigam plantações.

Os problemas atuais relativos à escassez de água e o receio planetário de que novas fontes sejam contaminadas aumentam as preocupações e incertezas inerentes à "Sociedade de Risco" (GUERRA, 2009).

A especialista Reolon, nesse sentido, observou que:

a sociedade atual vive o período pós-industrial, sendo caracterizada por Ulrich Beck como uma sociedade de risco, em que estão presentes duas espécies de riscos ecológicos, quais sejam: a) risco abstrato, que é invisível e imprevisível pelo conhecimento humano, com a probabilidade de existir por [meio] das verossimilhanças e evidências, mesmo não detendo o ser humano a capacidade perfeita de compreender esse fenômeno; b) risco concreto ou potencial, que é visível e previsível pelo conhecimento humano. A mesma autora afirmou que vive-se em uma sociedade de risco, uma sociedade que prioriza a evolução tecnológica e desconhece (ou até mesmo ignora) os reais perigos que isso pode ocasionar (REOLON, 2014, p. 01).

Para enfrentar esse contexto, enfatizou a importância do

princípio da precaução, que constitui uma alternativa viável para defesa do meio ambiente, sendo um instrumento que tem condições de proporcionar limites às ambições tecnológicas e científicas do ser humano, impondo medidas adequadas com o objetivo de afastar os perigos (REOLON, 2014, p. 01). 
Explicou a mesma autora que:

com base nesse princípio da precaução, sempre que houver perigo da ocorrência de dano grave, a ausência de certeza cientifica absoluta não deverá ser utilizada como razão para adiamento da adoção de medidas eficazes a fim de impedir a degradação ambiental (REOLON, 2014, p. 01).

\section{NORMAS E ACORDOS}

O artigo 25 da Declaração Universal dos Direitos Humanos de 1948 da Organização das Nações Unidas (ONU) prevê que: "toda pessoa tem direito a um nível de vida suficiente para lhe assegurar a si e à sua família a saúde e o bemestar..." (ONU, 1948, p. 13).-

A Carta Europeia da Água, proclamada pelo Conselho da Europa, em 1968, enfatizou por sua vez que não há vida sem água. Nessa direção, fez as seguintes ressalvas:

que a água é um bem precioso, indispensável a todas as atividades humanas; que os recursos de águas doces não são inesgotáveis; que é indispensável preservá-los, administrá-los e, se possível, aumentá-los; que alterar a qualidade da água é prejudicar a vida do Homem e dos outros seres vivos que dependem dela; que a qualidade da água deve ser mantida a níveis adaptados à utilização e deve, designadamente, satisfazer as exigências da saúde pública; que a manutenção de uma cobertura vegetal adequada, de preferência florestal é essencial para a conservação dos recursos de água; que os recursos aquíferos devem ser inventariados; que a boa gestão da água deve ser objeto de um plano promulgado pelas autoridades competentes; que a salvaguarda da água implica um esforço crescente de investigação, formação de especialistas e de informação pública; que água é um patrimônio comum, cujo valor deve ser reconhecido por todos; que cada um tem o dever de economizá-la e de utilizá-la com cuidado; que a gestão dos recursos de água deve inscrever-se no quadro da bacia natural, de preferência a ser inserida no das fronteiras administrativas e políticas; e que as águas não têm fronteiras, etc. (CARTA..., 1968, p. 01).

A Resolução da Assembleia Geral da Organização das Nações Unidas, n. 63/124, de 2009, sobre o Direito dos Aquíferos Transfronteiriços (ONU, 2009), estabeleceu várias obrigações entre os países signatários, dentre elas:

a) o dever de adotar medidas para proteger e preservar os ecossistemas dentro de um aquífero transfronteiriço ou dele dependente;

b) o dever de identificar e de proteger áreas de recarga e descarga do aquífero; 
c) o dever de prevenção, redução, controle da poluição e de adoção de uma abordagem de precaução;

d) e o dever de estabelecer e implementar planos de gerenciamento do aquífero e mecanismos de gerenciamento conjunto entre os envolvidos.

Em 2010, a Assembleia Geral da Organização das Nações Unidas aprovou a Resolução n. 64/292, que trata do direito humano à água e ao saneamento (ONU, 2010). Essa Resolução vincula-se aos principais tratados de direitos humanos, e atribuiu à água a classificação de bem insubstituível, alertando, oportunamente, que pode ser um recurso natural finito se não houver gestão sustentável.

Pela Constituição Federal de 1988, do Brasil, artigo 225 (BRASIL, 2019), todos têm direito ao meio ambiente ecologicamente equilibrado, impondo-se ao poder público e à coletividade, por conseguinte, o dever de defendê-lo e de preservá-lo para as presentes e futuras gerações.

Segundo Freitas (2011, p. 22-25), no Brasil, “a água [...] passou a ser um bem de domínio público [...]; entretanto, é dotado de valor econômico, segundo a Lei federal n 9.433/1997; o que na prática significa que o usuário deverá pagar pelo consumo".

Por sua vez, Carvalho Filho (2016, p. 995) observou que o Código Civil brasileiro, artigo 1.228, parágrafo $1^{\circ}$, estabelece que:

o direito de propriedade deve ser exercido em consonância com as suas finalidades econômicas e sociais e de modo que sejam preservados, de conformidade com o estabelecido em lei especial, a flora, a fauna, as belezas naturais, o equilíbrio ecológico e o patrimônio histórico e artístico, bem como evitada a poluição do ar e das águas.

Observou o especialista Godoy que os direitos às águas subterrâneas são difusos:

pois visam à proteção de interesses que não se inserem perfeitamente no padrão individualista, e representam, ao contrário, uma projeção de anseios sociais pela tutela de bens que não são nem meramente individuais nem sequer coletivos, mas sim pertinentes a cada ser humano e a todos ao mesmo tempo (GODOY, 2005, p. 01).

Considerando-se o fato de que existe uma boa legislação protetiva das águas no Brasil, matéria jornalística publicada pela agência BBC, Brasil, de 2018 destacou que "não existe qualquer possibilidade de privatização dos mananciais subterrâneos ou dos recursos hídricos brasileiros se for seguida a legislação vigente" (GOVERNO..., 2018, p. 01), conforme explicou o professor 
e pesquisador Rodrigo Lilla Manzione, da Faculdade de Ciências e Engenharia da Universidade Estadual Paulista (Unesp). Segundo o entrevistado, “a Constituição Federal e a Lei 9.433/97 (Lei das águas) [informam que] as águas são de domínio público, o que não permite qualquer direito de propriedade sobre elas" (GOVERNO..., 2018, p. 01).

Do ponto de vista jurídico, lembrou o professor Manzione que as águas subterrâneas estão sob o domínio dos Estados que as abrigam. Ou seja, cada Estado da federação pode ter uma legislação específica, e o Governo Federal não pode interferir. Consequentemente, "para mudar essa situação e tornar os aquíferos passíveis de privatização seriam necessárias mudanças na Constituição por meio de uma Proposta de Emenda Constitucional (PEC)" (GOVERNO..., 2018, p. 01). Concluindo, o pesquisador Manzione afirmou que "o sistema brasileiro é avançado e maduro o suficiente de forma a não permitir eventuais retrocessos na gestão dos recursos hídricos" (GOVERNO..., 2018, p. 01).

No levantamento feito pelos analistas Coelho e Silva (2008) identificou-se que as Províncias de Corrientes, Entre Rios e Missiones, onde está localizado o aquífero Guarani na Argentina, possuem legislações sobre águas subterrâneas.

No Brasil, segundo os mesmos autores, todas as águas passaram para o domínio público com a promulgação da Constituição Federal de 1988. Nessa direção, "as correntes de água que banhem mais de um Estado, e que se estendam a território estrangeiro ou, sirvam de limites com outros países, são consideradas bens da União, conforme dispõe o artigo 20, inciso III, da Constituição Federal" (COELHO; SILVA, 2008, p. 10)

De acordo ainda com Coelho e Silva (2008, p. 12) "no Paraguai, a Lei n. 1.561/2000, também conhecida como a Lei-Mãe Ambiental, instituiu o Sistema Nacional do Ambiente (SISNAM), o Conselho Nacional do Ambiente e a Secretaria do Ambiente".

Já no Uruguai, em 31 de outubro de 2004, foi realizado um plebiscito, no qual mais de 64\% dos eleitores apoiaram a Reforma Constitucional que definiu a água como um bem público. O texto constitucional uruguaio estabelece que "a água é um recurso natural essencial para a vida"; e constituem "direitos humanos fundamentais" o acesso à água e a todos os serviços de saneamento (COELHO; SILVA, 2008, p. 13). 


\subsection{PONTO DE MUTAÇÃO}

Antes de 2010 havia, politicamente, entre Brasil, Paraguai Argentina e Uruguai, um Sistema Aquífero de Estados, conforme sugere a classificatória proposta por Hedley Bull (2002).

O sistema internacional ou sistema de Estados, segundo a classificatória desse autor, configura-se quando dois ou mais Estados têm suficiente contato entre si, e sofrem impacto recíproco de suas decisões.

Entretanto, nesse cenário, as relações internacionais são aleatórias envolvendo temas diversos que envolvem conflitos que serão resolvidos por meio da guerra ou da diplomacia. Nesses termos, constata-se que o conceito de sistema internacional não difere da abordagem hobbesiana.

Diferentemente, a sociedade internacional ou sociedade de Estados existe quando um grupo de Soberanos, conscientes de certos valores e interesses comuns, formam uma sociedade, ficando ligados por um conjunto comum de regras e instituições.

Nesse cenário, as relações internacionais são praticadas não só visando à resolução de conflitos, mas fundamentalmente à cooperação de interesses mútuos. Na sociedade de Estados, o respeito a determinados valores comuns é fator preponderante (BULL, 2002).

Nessa mesma perspectiva teórica, até o ano de 2010 os quatro países beneficiados pelo Sistema Aquífero Guarani apresentavam um conjunto de normas não harmônicas relativas à gestão dos recursos hídricos subterrâneos. Admitiam os analistas nesse período que apesar da existência de diferentes sistemas jurídicos com uma complexa distribuição de poderes e competências, havia aspectos importantes que deviam ser considerados para a consecução de políticas compartilhadas de gestão da água. Um ponto em comum entre os países do Sistema Aquífero Guarani naquele momento é que eles já consideravam em seus ordenamentos jurídicos a água como um bem público (ESTRADA, 2005).

A grande mudança geopolítica ocorreu mesmo a partir de 2010 quando foi instituída a Sociedade Aquifera de Estados fixando uma nova ordem ecológica e política na região fronteiriça.

Animados pelo espírito de cooperação e de integração e com o propósito de ampliar o alcance de suas ações concertadas para a conservação e aproveitamento sustentável dos recursos hídricos transfronteiriços do Sistema 
Aquífero Guarani os quatro países da região acordaram que o Sistema Guarani é um recurso de comum propriedade dos países locais e que cada um deles poderá usar da melhor maneira o estoque natural de águas de acordo com suas disposições constitucionais e legais e em conformidade com as normas de direito internacional aplicáveis.

Declara o mesmo documento internacional que em cada país a utilização dos recursos hídricos deverá priorizar o aproveitamento de forma racional e sustentável e respeitar a obrigação de não causar prejuízo sensível às demais partes, nem ao meio ambiente.

Também, quando se causar prejuízo sensível à outra parte e ao meio ambiente, a outra parte responsável pelo prejuízo deverá adotar todas as medidas para reduzi-lo ou eliminá-lo. Além disso, cada parte deverá informar às outras partes todas as atividades em seu território que possam ter efeitos ou impactos no sistema para além de suas fronteiras. A informação seguirá acompanhada de dados técnicos disponíveis, incluídos os resultados de uma avaliação dos efeitos ambientais para que as partes que receberem a informação possam avaliar os possíveis efeitos de tais atividades e obras.

Em caso de suspeita de riscos, de uma atividade ou obra, ocasionados por uma das partes, com eventual prejuízo, poderá solicitar-se dados técnicos disponíveis, incluídos os resultados de uma avaliação dos efeitos negativos. Oportunamente, futuros conflitos devem ser resolvidos através da arbitragem internacional.

Também as partes se comprometeram a estabelecer programas de cooperação com o propósito de ampliar o conhecimento técnico e científico sobre o Sistema Aquífero Guarani; promover o intercâmbio de informações sobre as práticas de gestão, bem como desenvolver projetos comuns.

Todas essas considerações normativas aprovadas pelo Senado brasileiro em 2017 reforçam a teoria classificatória do analista Hedley Bull (2002, p. 85-86), uma vez que:

$\mathrm{Na}$ sociedade internacional os principais responsáveis pela função de ajudar a tornar as regras efetivas são seus próprios membros - os Estados soberanos. Isto ocorre em virtude da inexistência de um governo supremo, que no estado moderno pode exercer essa função, ou de um grau de solidariedade entre os Estados como o que caracteriza, nas sociedades primitivas sem estado, a execução dessa atividade pelos grupos politicamente competentes. Neste sentido, na sociedade dos Estados, as instituições mais importantes são os próprios Estados. São 
eles que exercem a função de formular as regras, ou legislar, manifestando a sua concordância. As normas de aplicação geral, como as regras de coexistência, nascem do costume e da prática estabelecida, sendo em alguns casos confirmadas por convenções multilaterais.

\section{CONCLUSÃO}

O inventário das ideias desse estudo deixou claro que o fio condutor ou princípio preponderante que anima o debate da tridimensionalidade do direito às águas subterrâneas do aquífero Guarani é a sustentabilidade.

Os estudos contemporâneos que utilizam esse princípio transcendental enfatizam a ideia de que o ambiente compõe um sistema complexo e articulado, motivo pelo qual é preciso considerar a interface da água como recurso ambiental e econômico, garantindo-se estrategicamente a sua interconexão com outros saberes e legislações internacionais.

Nessa perspectiva teórica e política, as legislações já existentes em estados, províncias e governos estaduais precisam ser eficazes no sentido de promover garantias ecológicas sem perder de vista os princípios subsidiários da prevenção, da precaução, da informação, da notificação ambiental, e da cooperação internacional, entre outros, que conjuntamente atuam em favor do equilíbrio ideal entre a utilização econômica e a preservação do bem ecológico visando as presentes e as futuras gerações.

Em nome da sustentabilidade é preciso a intervenção mais incisiva do Estado brasileiro em seu território hídrico, fomentando pesquisas sistemáticas que tragam melhores conhecimentos sobre os potenciais dos aquíferos; ao mesmo tempo, o Estado deve executar medidas urgentes visando frear o risco de contaminação das reservas subterrâneas, uma vez que cada aquífero é único na Natureza e possui características próprias.

Além disso, o Estado brasileiro deve propor políticas públicas de Estado e não de governo, voltadas ao desenvolvimento e à proteção ambiental de suas reservas, especialmente distribuindo incentivos fiscais em favor do reflorestamento, e criando novas áreas de proteção hidro ambiental; sendo necessário, concomitantemente, ainda, planejar o uso do solo em zonas de afloramento e de recarga do Aquífero Guarani; priorizar o uso equitativo das águas subterrâneas e superficiais, evitando o desperdício e a contaminação; e investir constantemente no papel transformador da educação ambiental. 


\section{REFERÊNCIAS}

ÁGUA e cultura. Revista Página 22. Fundação Getúlio Vargas: Centro de Estudos em Sustentabilidade, São Paulo: 2014. Disponível em: http://pagina22. com.br/2014/05/08/agua-e-cultura. Acesso em: 30 jul. 2018.

BACCI, D. de la C.; PATACA, E. Educação para a água. Estudos avançados [online], São Paulo, vol. 22, nº3, p. 211-226, 2008. Disponível em: http://www. scielo.br/pdf/ea/v22n63/v22n63a14.pdf. Acesso em: 30 jul. 2018.

BRASIL. Constituição da República Federativa do Brasil de 1988. 46a ed. São Paulo: Atlas, 2019.

BULL, H. A sociedade anárquica: um estudo sobre a ordem na política mundial. Brasilia: UnB, 2002.

CARTA Europeia da Água do Conselho da Europa, 6 de maio de 1968, 1968. Disponível em: https://www.infopedia.pt/\$Carta-europeia-da-agua. Acesso em: 30 jul. 2018.

CARVAlHO, J. R. Tratado regulamentando a exploração do Aquífero Guarani pelos países do MERCOSUL. Campinas: FACAMP, 2008. Disponível em: https://pt.scribd.com/document/29059750/Aquifero-Guarani. Acesso em: 30 jul. 2018.

CARVAlHo FILHO, J. dos S. Manual de Direito Administrativo. $30^{\mathrm{a}}$ ed. São Paulo: Atlas, 2016.

COELHO, A. M.; SILVA, S. Aspectos internacionais do Aquífero Guarani. 2008 Disponível em: www.publicadireito.com.br/conpedi/manaus/arquivos/ anais/manaus. Acesso em: 30 jul. 2018.

DECLARAÇÃO de Dublin sobre água e desenvolvimento (1992). 1992. Disponível em: http://www.agda.pt/declaracao-de-dublin.html. Acesso em: 30 jul. 2018.

ECOA (Ecologia e Ação). Institucional. Brasil, 2018. Disponível em: http:// ecoa.org.br/ecoa-institucional/. Acesso em: 30 jul. 2018.

EFING, A. C.; RESENDE, A. C. L. de. Educação para o consumo consciente: um dever do estado. RJLB, ano 2, no 1, 2016. Disponível em: http://www. cidp.pt/publicacoes/revistas/rjlb/2016/1/2016_01_0713_0746.pdf. Acesso em: 30 jul. 2018. 
ESTRADA, M. M. P. As águas subterrâneas do direito internacional ambiental: o Aquífero Guarani. Programa de Pós-Graduação em Direito/UFRGS, João Pessoa, v. 3, n. 6, 2005. Disponível em: http://www.seer.ufrgs.br/index.php/ ppgdir/issue/view/2512/show'Toc. Acesso em: 30 jul. 2018.

ESTUDO mostra que o Aquífero Guarani está contaminado por agrotóxicos. Revista eletrônica EcoDebate, Mangaratiba, 19 maio 2011. Disponível em: https://www.ecodebate.com.br/. Acesso em: 30 jul. 2018.

FREITAS, W. P. de. (org). Água: aspectos jurídicos e ambientais. Curitiba: Juruá, $3^{\mathrm{a}}$ ed. 2011.

GODOY, G. G. de. A fundamentalidade do direito à água e sua titularidade difusa. UFPR, Revista de Direito, Curitiba, v. 43, n. 0, 2005, p. 01. Disponível em: https://revistas.ufpr.br/direito/article/view/7008/4985. Acesso em: 30 jul. 2018.

GOVERNO poderia privatizar Aquífero Guarani como sugerem mensagens nas redes? BBC NEWS BRASIL Por Evanildo da Silveira, 2018. Disponível em: https://www.bbc.com/portuguese/brasil-43164069. Acesso em: 30 jul. 2018.

GUERRA, S. Crise ambiental na sociedade de risco. Lex Humana, Petrópolis, n. 2, 2009. Disponível em: https://digitalis-dsp.uc.pt/jspui/ bitstream/10316.2/33889/1/LH1-2_artigo8.pdf. Acesso em: 30 jul. 2018.

HARDIN, G. A. tragédia dos comuns. Science, v. 162, n. 3859, p. 1243-1248, dez. 1968. Disponível em: http://www.garretthardinsociety.org/articles/art_ tragedy_of_the_commons.html. Acesso em 30 jul. 2018.

HOBBES, T. Leviatã. Tradução de João P. Monteiro e Maria Beatriz N. da Silva. São Paulo: Martins Fontes, 2003.

MONTARROYOS, H. E. Teoria pluridimensional do Direito: variantes e aplicabilidade. Revista Jus Navigandi, Teresina, ano 17, n. 3216, p. 01, abr. 2012. Disponível em: https://jus.com.br/artigos/21567. Acesso em: 30 jul. 2018.

OEA (ORGANIZAÇÃO DOS ESTADOS AMERICANOS). Aquífero Guarani: Programa Estratégico de Ação. Argentina, Brasil, Paraguai e Uruguai. Montevidéu: OEA, 2009. 424 p. CD-ROM.

ONU (ORGANIZAÇÃO DAS NAÇÕES UNIDAS). Declaração Universal dos Direitos Humanos de 1948, 1948, Nova York, p. 13. Disponível em: https:www. portaleducação.com.br/home/artigo/direito. Acesso em 29 jul. 2018. 
ONU (ORGANIZAÇÃO DAS NAÇÕES UNIDAS). Site da instituição, leis e documentos diversos disponíveis. Disponível em: https://nacoesunidas. org/conheca/. Acesso em: 03 jul. 2018.

ONU (ORGANIZAÇÃO DAS NAÇÕES UNIDAS). Assembleia Geral. Resolução 63/124 de 2009 sobre O Direito dos Aquíferos Tranfronteriços. 2009. Disponível em: htpp://www.un.org/en/ga/sixth/66/TransAquifer.html. Acesso em: 01 abr. 2016.

ONU (ORGANIZAÇÃO DAS NAÇÕES UNIDAS). Assembleia Geral. Resolução 64/292 de 2010 sobre O Direito Humano à Água e Saneamento. 2010. Disponível em: www.liberato.com.br/sites/defaut/files/luis_roberto_ moraes_parte_4.pdf. Acesso em: 01 abr. 2016.

REALE, M. Teoria do Direito e do Estado. São Paulo: Martins, 1960.

REALE, M. Filosofia do Direito. 20. ed. São Paulo: Saraiva, 2002.

REOLON, C.C.C. Sociedade de risco e meio ambiente: o princípio da precaução e a inversão do ônus da prova. ConteúdoJurídico, Brasília-DF, out. 2014. Disponível em: http://www.conteudojuridico.com.br/?artigos\&ver=2.50281\&seo=1. Acesso em: 30 jul. 2018.

RESENDE, A. C. L. de. A educação para o consumo consciente no ensino infantil. Revista da AJURIS, Porto Alegre, v. 40, n. 131, set. 2013a. Disponível em: http://www.ajuris.org.br/OJS2/index.php/REVAJURIS/article/view/278. Acesso em: 30 jul. 2018.

RESENDE, A. C. L. de. A proteção do meio ambiente no sistema interamericano de direitos humanos a partir do direito à educação. Revista de Direito Internacional, Brasília, v. 10, n. 2, 2013b. Disponível em: https://bdjur.stj.jus. br/jspui/bitstream/2011/71831/protecao_meio_ambiente_resende.pd. Acesso em: 30 jul. 2018.

SAMPAIO, R. S. da R.; LAMARE, J. M. de; KLOSS, V. D. O. Regulação ambiental e a tragédia dos anti-bens comuns: análise de eficiência e efetividade aplicável ao regime de competência em matéria de licenciamento ambiental. Revista Direito Ambiental e Sociedade, Caxias do Sul, v. 6, n. 1, jan./jun. 2016. Disponível em: www.ucs.br/etc/revistas/index.php/direitoambiental/ issue/view/192/. Acesso em: 30 jul. 2018. 
SOUZA, L. C. de. Águas subterrâneas e a legislação brasileira. Curitiba: Juruá. 2009.

USO incorreto da água causa superexploração do Aquífero Guarani. Jornal do Barão, (online), 2005. Disponível em: https://baraodemaua.br/comunicacao/ publicacoes/jornal/2005/junho/empresas.htm. Acesso em: 30 jul. 2018. 